DOI: https://doi.org/10.47405/mjssh.v6i12.1218

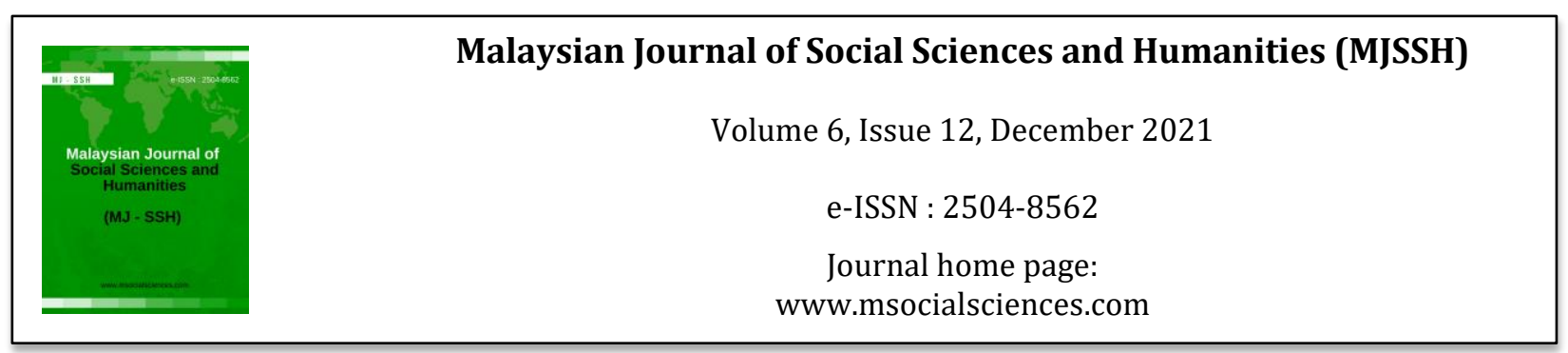

\title{
Influence of Social, Economic and Family Factors on Alcohol Consumption: A Systematic Review
}

\author{
Rubiah Anak Ajan', Vivien Yew Wong Chin'1, Abd Hair Awang1 \\ ${ }_{1}^{1}$ Faculty of Social Sciences and Humanities, The National University of Malaysia (UKM), Malaysia \\ Correspondence: Rubiah Anak Ajan (email: p93263@siswa.ukm.edu.my)
}

\begin{abstract}
Alcohol consumption is increasing global and it is the reasons for large number of death. According to WHO 2018, 3.3 million deaths worldwide related to alcohol consumption was recorded in 2016 alone. The use of alcohol has a serious impact on lives which leads to poverty, road accident, injury, domestic violence and crime. This study reviews the literature to find the predictors and provide direction for future work. Using a systematic literature review, several filtering process using selected keywords a total of 20 articles were reviewed. The findings showed that most of studies were conducted in Europe followed by US. There are limited number of reviewed studies and the predictors are mainly related to socio-economic status, social factors, demographics, social networking sites, family factor and stress. Findings were discussed and direction of future work were highlighted. More studies are needed to understand the predictors of alcohol consumption in the community as large. Due to limited studies related alcohol consumption in the developing countries, topic of alcohol use are needed to be investigated in order to fill in the gap in the literature. It is important to identify and understand factors causes alcohol consumption which leads to social and health problems in the society. By identifying these predictors could reduce a potential risk when individuals are exposed to harmful behavior.
\end{abstract}

Keywords: socio-economic status, alcohol consumption, social factors, stress, family factor

\section{Introduction}

Alcohol consumption is one of the concern for public health authority, families, and countries. It has several negative consequence on health, economy, and society. According to United Nation, Alcohol consumption is responsible of 3.3 million death annually worldwide (Quiroga et al., 2018). The use of alcohol in the community is the reasons of 200 types diseases as well as injuries caused by road accidents (World Health Organization, 2018). The average of drinking is increasing among adult and underage and it could increase more in this difficult time of stress during COVID 19 and the lockdown of businesses and countries. Quantity of consumption increased drastically during this outbreak as solution to cope with their depression which was forced to stay put, socially not active and not being allowed to be in public place for a longer time (Tran et al., 2020). The consumption of alcohol when individuals are under stress is a form of releasing that particular pressure they might want to get rid of for not thinking about the problems they have to endured even though the impact of alcohol on body system are in short period of time (Keyes et al., 2012). Previous studies indicate that individual who are emotionally instable or under stress are six time more likely to drink alcohol (Stapinski et al., 2016). Consistent with the findings of Dvorak et al. (2016) found that those experienced unstable 
emotion are associated with alcohol consumption. According to World Health Organization (2018), poverty and loss of job is related to alcohol consumption. Those with low socioeconomic are more likely to engage in alcohol consumption which results in economic deprivation due to continuous of risky behavior (Beard et al., 2016).

According to Shin et al. (2021) alcohol consumption is one of the leading cause of preventable death in the US in which resulted a total of 88,000 mortality annually as well as lead to the country economic burden of USD 250 billion including medical costs, deaths and declines in productivity at workplace. Moreover, the burden of alcohol consumption in the UK is estimated around Euro 3 billion per year (Balakrishnan et al., 2009). Researchers believe that the socio-economic status is an essential predictor of higher alcohol consumption. For example, some studies found that the high socioeconomic status is the reason for increased in alcohol consumption (Collins, 2016; Juliana Gabrielle et al., 2016; Stapinski et al., 2016). On the other hand, some studies argued the opposite. Those with low socio-economic status tend to drink more alcohol (Beard et al., 2019; Huckle et al., 2018).

There is contradiction in the literature regarding the role of socio-economic status and social factors and their effects on alcohol consumption. To understand the effect of socio-economic status and other variables in the literature on the alcohol consumption, this study aims to review the literature and understand the predictors of alcohol consumption from social perspective. This paper consists of five sections. The presents section has provided the background of this paper. This is followed by the research methodology and the summary of the reviewed articles. The findings of this paper is presented in figures. The last section presents the conclusion, limitation, and the direction for future research.

\section{Method}

This study is a quantitative and it conducts a literature review using available articles that are related to the topic. Keywords such as social factors, alcohol consumption, SES, stress, family and a combination of these words were used to identify the related articles. Search for the articles was conducted using google scholar since all the articles are indexed in this search engine. As a result, a total of 171 articles were identified. Three screening were applied to identify the most related articles. In the first screening the non-English, duplicated, and outdated articles were removed. This has resulted in removing 133 articles. The remaining articles were further screened by reading the abstract and the title. This further resulted in removing 15 articles. The last screening included a full reading of all the articles and this has reduced the articles to 20 related articles. The articles are analysed and important information are extracted. The data of the articles are analysed using excel sheet to present the findings. Figure 1 shows the process of filtering the articles.

Figure 1: Filtering process

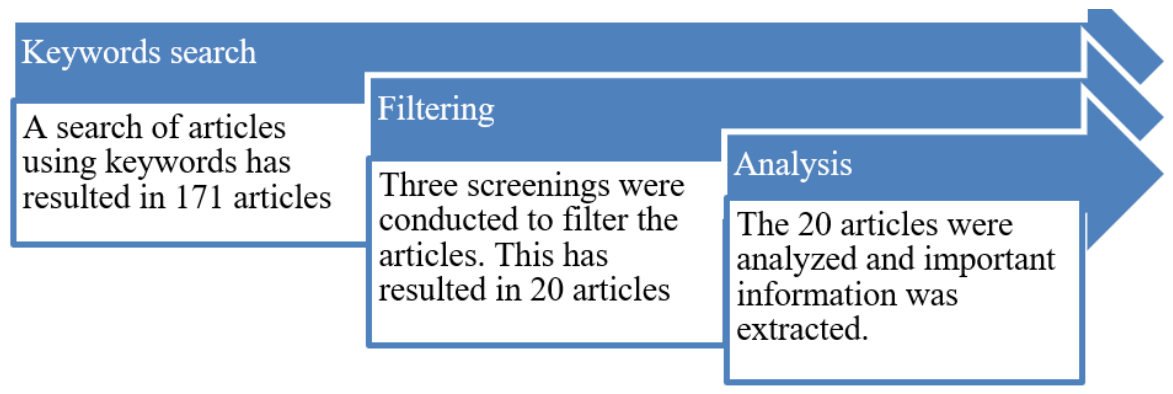

\section{Results}

The literature into alcohol consumption can be divided into four main themes. The first theme related the alcohol consumption to social factors. For example, in Russia, the study of Murphy et al. (2012), alcohol consumption was related to social factors. The findings showed that males and smokers are 
more likely to consume alcohol. Ajan and Hanafiah Juni (2016) in Malaysia found that social factors is responsible for several behaviour such as smoking and alcohol consumption. Robinson et al. (2016) in UK pointed out that the increase in social ingratiation will lead to more alcohol consumption. Similar findings in Sweden was derived from the study of Agahi et al. (2019) who found that social interaction increases the alcohol consumption. McCartney et al. (2016) found that the changes in income, social, and demographic factors has affected the rate of death caused by alcohol consumption. Social factor also were the predictors of alcohol consumption in the study of Mehanović et al. (2020) in Slovenia where the findings indicate that parent alcohol consumption, low monitoring, peer, belief, and refusal skills are important factors for alcohol consumption.

Table 1: Summary of Extracted Articles

\begin{tabular}{|c|c|c|c|}
\hline Author/ year & I.V. & D.V & Findings \\
\hline $\begin{array}{l}\text { (Agahi et al., 2019; Murphy et al., } \\
\text { 2012; Robinson et al., 2016) }\end{array}$ & $\begin{array}{l}\text { Social } \\
\text { factors }\end{array}$ & $\begin{array}{l}\text { Alcohol } \\
\text { consumption }\end{array}$ & $\begin{array}{l}\text { Social factors have an } \\
\text { important effect on alcohol } \\
\text { consumption. }\end{array}$ \\
\hline $\begin{array}{l}\text { (Ajan \& Hanafiah Juni, 2016; } \\
\text { Beard et al., 2019; Collins, 2016; } \\
\text { Huckle et al., 2018; Juliana } \\
\text { Gabrielle et al., 2016; Mehanović } \\
\text { et al., 2020; Moan \& Halkjelsvik, } \\
\text { 2020; Sadler et al., 2017; } \\
\text { Stafström \& Agardh, 2013; } \\
\text { Stapinski et al., 2016; Thern \& } \\
\text { Landberg, 2020) }\end{array}$ & $\begin{array}{l}\text { Socio- } \\
\text { economic } \\
\text { factors }\end{array}$ & $\begin{array}{l}\text { Alcohol } \\
\text { consumption }\end{array}$ & $\begin{array}{l}\text { Findings regarding the socio- } \\
\text { economic status is contradicted. } \\
\text { Some studies found that high } \\
\text { socio-economic status } \\
\text { consumes more alcohol. On the } \\
\text { other hand, other found the } \\
\text { lower socio-economic status are } \\
\text { more consuming and drinking } \\
\text { alcohol. }\end{array}$ \\
\hline (McCartney et al., 2016) & Demographic & $\begin{array}{l}\text { Alcohol } \\
\text { consumption }\end{array}$ & $\begin{array}{l}\text { The changes in income, social, } \\
\text { and demographic factors have } \\
\text { affected the rate of death caused } \\
\text { by consuming alcohol. }\end{array}$ \\
\hline $\begin{array}{l}\text { (Geusens et al., 2017; Quiroga et } \\
\text { al., 2018) }\end{array}$ & $\begin{array}{l}\text { Social } \\
\text { networking } \\
\text { site }\end{array}$ & $\begin{array}{l}\text { Alcohol } \\
\text { consumption }\end{array}$ & $\begin{array}{l}\text { Exposure but not self-sharing } \\
\text { has impact on alcohol } \\
\text { consumption. Personality did } \\
\text { not moderate the effect. }\end{array}$ \\
\hline $\begin{array}{l}\text { (Clay \& Parker, 2018; Goodman } \\
\text { et al., 2017) }\end{array}$ & Stress & $\begin{array}{l}\text { Alcohol } \\
\text { consumption }\end{array}$ & $\begin{array}{l}\text { Group under stress showed } \\
\text { more desire to drink alcohol. }\end{array}$ \\
\hline (Vargas-Martínez et al., 2020) & Family factor & $\begin{array}{l}\text { Alcohol } \\
\text { consumption }\end{array}$ & $\begin{array}{l}\text { Older with larger pocket money } \\
\text { and family who drink alcohol } \\
\text { are more consumer of alcohol. }\end{array}$ \\
\hline
\end{tabular}

The second theme is with the opinion that alcohol consumption is more related to the SES. For instance, Sadler et al. (2017) in UK found that socio-economic status gradient is a critical reasons for the alcohol consumption. In the study of Stafström and Agardh (2013) in Uganda, the finding showed that education of the head of house as well as gender and religion, and family connection and relationship has important effect on alcohol consumption. Collins (2016) in US found that those with high socio-economic status tend to consume more alcohol. Similar findings were derived by Juliana Gabrielle et al. (2016) in Brazil who found that high socio-economic status and male are more likely to drink, and in the study of Stapinski et al. (2016) in UK who found that high income are more likely to drink to increase self-confidence. Moreover, those who have low income drink to adjust the mood and socio economic and demographic has big role in drinking patterns. On the other hand, (Huckle et al. 2018) in a global study found that lower socio-economic status lead to more alcohol consumption. Similarly, the findings of the study of Beard et al. (2019) in UK indicate that those in lower social grade drink more than those in upper one.

The third theme is the effect of social networking on the consumption. In the study of Geusens et al. (2017) in Belgium, the findings showed that exposure but not self-sharing has impact on alcohol consumption. Personality did not moderate the effect. In Spain, Quiroga et al. (2018) found that due to 
social network, there is high alcohol consumption among female. Lower intensity of the friendship and relationship with peers as well as the structure of the class are important predictor of alcohol consumption.

The fourth theme is related to the social stress and anxiety. In the study of Clay and Parker (2018) in UK, the findings showed that group under stress showed more desire to drink alcohol. Goodman et al. (2018) in US also found that high alcohol consumption affect the relationship between social anxiety and quality of everyday social interaction.

\section{Location of the Studies}

The findings of the literature can be classified based on the approach of the study, location, predictors, respondents, and data analysis tools. In the following sections, the findings are presented. In this study showed that there were eight countries involved in this study which was selected systematically using filtering process mentioned in the method. The findings of this study indicates that the highest percentage of studies (35\%) were conducted in the UK followed by US (10\%) and Spain (10\%). These are countries that dominated the area of alcohol consumption which comprised of many aspects. Distribution of the study based on countries can be seen in Table 2 .

Table 2: Location of the Studies

\begin{tabular}{lll}
\hline Countries & Number of studies & Percentage \\
\hline UK & 7 & $35 \%$ \\
US & 2 & $10 \%$ \\
Spain & 2 & $10 \%$ \\
Sweden & 2 & $10 \%$ \\
Slovenia & 1 & $5 \%$ \\
Norway & 1 & $5 \%$ \\
Russia & 1 & $5 \%$ \\
Uganda & 1 & $5 \%$ \\
Belgium & 1 & $5 \%$ \\
\hline
\end{tabular}

\section{Predictor of Alcohol Consumption}

Based on the reviewed studies, there are several important variables that have been used and associated with Alcohol consumption and drinking. The most frequently used variable is the socioeconomic status of the respondents. This is followed by social factors, demographics such as age, gender, and education. Stress and social networking site as well as the family factors were also significant predictors of Alcohol consumption. Figure 2 shows the predictors of alcohol consumption.

Figure 2: Predictors of Alcohol Consumption

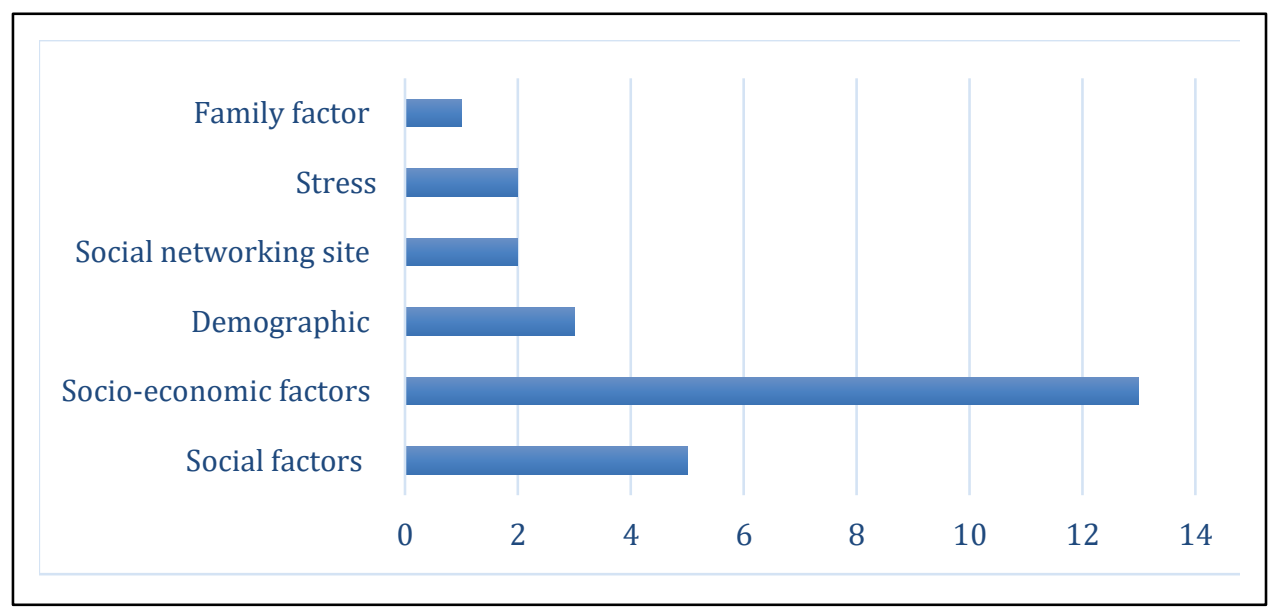




\section{Participant}

The findings of this reviewed studies focused in general on students. Most of the studies collected data using students population followed by employee and adolescents population where the focus on drinkers. This is followed by general respondents which has accounted to only 5\% of the reviewed studies. Table 3 shows the respondents of the reviewed studies.

Table 3: Participant of the Studies

\begin{tabular}{ccc}
\hline Categories & Number of studies & Percentage \\
\hline Student & 11 & $61 \%$ \\
Adolescents & 3 & $17 \%$ \\
Employee & 3 & $17 \%$ \\
General & 1 & $5 \%$ \\
\hline
\end{tabular}

\section{Year of Publication}

The year of publication is presented in Figure 3. It can be seen that the highest percentage of studies were conducted between 2013 and 2017. Number of studies has increased in 2020 and this could be due to the outbreak of COVID 19.

Figure 3: Year of Publication of the Reviewed Studies

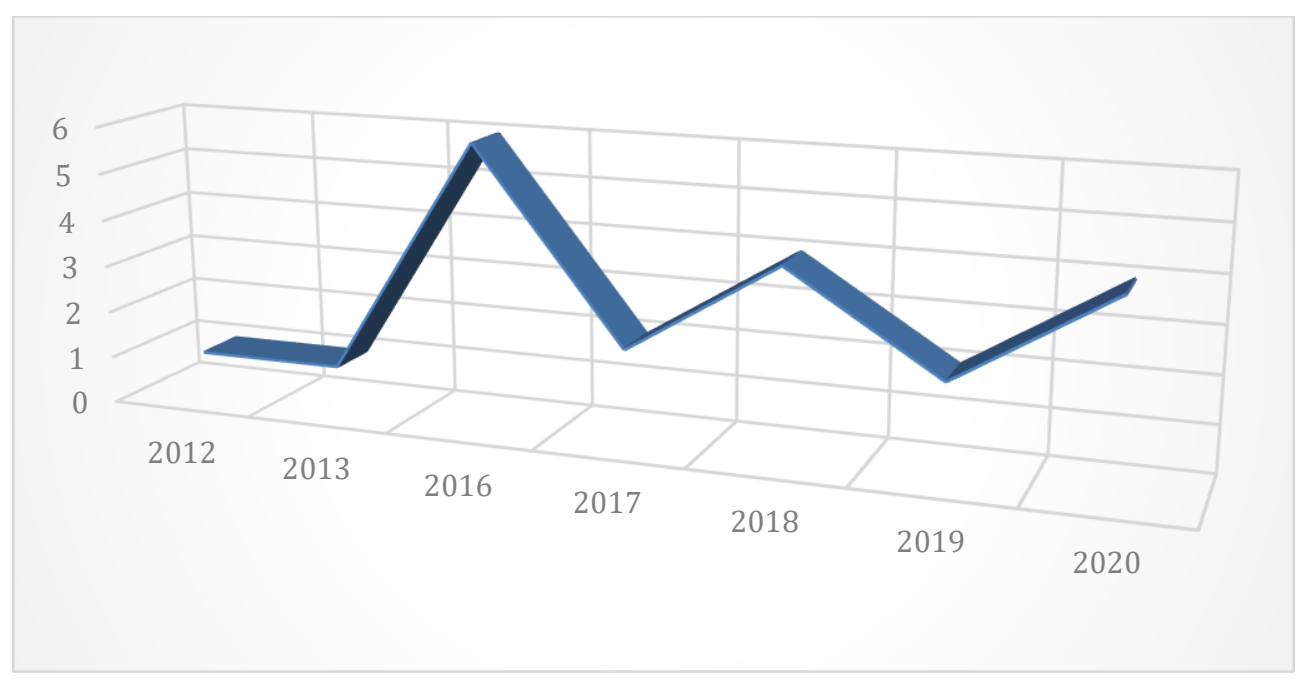

\section{Approach of the Reviewed Studies}

Among the reviewed studies, the majority (86\%) were empirical studies and conducted using data that are collected from the respondents. Only $(14 \%)$ of the studies are review studies that aimed to gauge the understanding of previous studies and present the direction for future work. Table 4 shows the approach of the reviewed studies.

Table 4: Approach of the Reviewed Studies

\begin{tabular}{ccc}
\hline Categories & Number of studies & Percentage \\
\hline Empirical & 18 & $86 \%$ \\
Review & 2 & $14 \%$ \\
\hline
\end{tabular}




\section{Sample Size}

In this findings showed several of total number with regards to sample size that was being used in previous study using the quantitative approach. Out of the empirical studies, the study found that sample size used in previous studies ranged between 39 and 57,807 respondents. The mean score value of the sample size obtained in these studies is 8453 . Therefore, figure 4 shows the variety of total sample size of the reviewed studies.

Figure 4: Sample Size of the Reviewed Studies

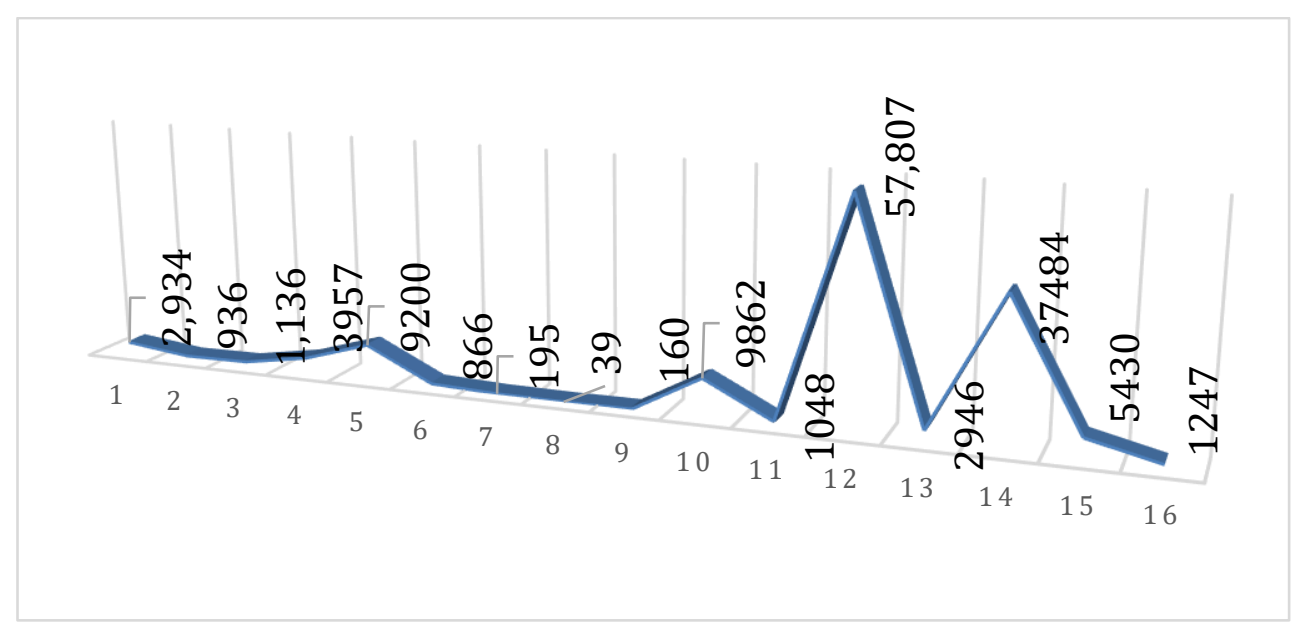

\section{Data Analysis Approach and Tools}

The previous studies have deployed mainly the SPSS software to conduct their studies. The majority has deployed the SPSS to understand the casual relationship between the independent variable and Alcohol consumption. In addition, SPSS software was widely used in the reviewed studies due to the fact that the researchers were examining for the factors caused alcohol consumption in their selected population. The descriptive studies were less than the causal studies and STATA software was used in a little of studies. Figure 5 shows the data analysis approach and tools.

Figure 5: Data Analysis Approach and Tools

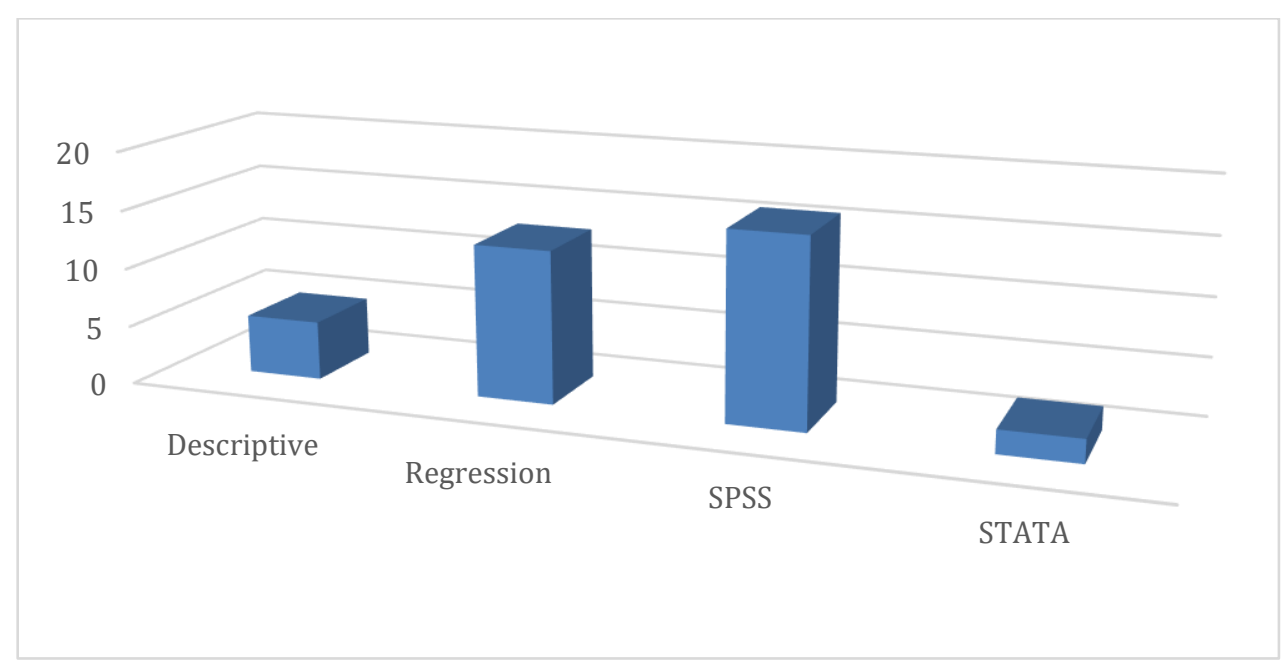

\section{Conclusion}

This study was conducted to review the existing literature regarding the effect of socio-economic factors on the alcohol consumption. The study also aimed to provide the future researchers with 
direction and the status of the alcohol consumption. A systematic literature review was conducted to assess the literature and extract the related articles. As a result, a total of 20 articles were reviewed and important information were extracted. The finding of this study showed that the studies on alcohol consumption has been carried out in developed countries such as UK, US, and Spain while few studies were conducted in the developing countries. Findings also showed that there are several predictors of alcohol consumption such as socio-economic factors, social factors, demographics, social networking site, and stress as well as family factors. Findings also showed that the majority of respondents in previous studies are students and number of studies have increased during 2020. Few of the reviewed studies were a review of the literature and the sample sizes of the empirical studies were large. The findings also showed that SPSS dominated the method of analysis in the reviewed studies.

This study is limited to the search criteria and keywords that have been used. It is also limited to the number of articles that has been extracted. As a way forward, future studies are recommended to examine the alcohol consumption in developing countries. Due to social and health problems caused by the use of alcohol in developing countries, there is need for future studies to study these factors in understudied population which provides significant findings. Future studies are also recommended to examine the effect of socio-economic factors. The literature is contradicted in term of the effect of socio-economic status on Alcohol consumption, future studies are recommended to conduct more studies to understand the nature of the relationship between socio-economic status and alcohol consumption. Further, future studies are suggested to deploy moderating variables such as the demographic information i.e., age, gender, education, occupation, income, and marital status. This due to the fact that most of previous study found that there is relationship between alcohol consumption with demography and socioeconomic factors. Other important variable that can be used is the family and peer influence. Effective intervention are based on early information related the community lifestyle, health issues and social problems caused by alcohol consumption. The risk will continue high when alcohol use is adopted in the community without proper guidelines. These factors beneficial when considering effective community based intervention to reduce alcohol risk in the community.

General population studies which include all the class in the society are recommended for future studies. Majority of previous studies have focused only on students while other class of the population has not been researched. In addition, there is need the study on alcohol consumption among adults as at this stage an individuals are considered have full control over their lives as their decision making could have an impact to their future wellbeing. Thus, more studies on Alcohol consumption and the link with the outbreak of COVID 19 is needed. During the outbreak, the stress has increase due to the lockdown. This might lead people to stay home and drink more because of anxiety and stress. The future studies are suggested to deploy second generation of data analysis software such as Structural Equation Modeling (SEM) because this software has the capabilities of analysing complex model. Structural Equation Modeling could be used with mediating and moderating predictors in order to have better understanding the relationship with alcohol consumption. Previous study indicates that structural Equation Modeling is a popular tools in predicting alcohol consumption.

The findings of this study can be of benefit for decision makers who are concerns about the public health. As people spent more time at home than before, unhealthy behavior like alcohol consumption is slowly developed in the community which this might expose people to a greater risk of developing health issues as well as could trigger domestic violence, crime, poverty and loss of productivity in performing their work from home tasks. By staying at home longer than before also caused stress and anxiety due to not being able to engage in social activities. This result in decrease of wellbeing of the person. During the COVID19, decision makers are recommended to broadcast entertaining programs to reduce the stress among the population. They are also advised to increase the awareness by launching an awareness campaign about the alcohol consumption and its harmfulness.

\section{Acknowledgement}

The publication of this paper was supported by MPOB-UKM Endowed Chair, Research Grant EP2019-054. 


\section{References}

Agahi, N., Dahlberg, L. \& Lennartsson, C. (2019). Social integration and alcohol consumption among older people: A four-year follow-up of a Swedish national sample. Drug and Alcohol Dependence, 196(January): 40-45. doi:10.1016/j.drugalcdep.2018.12.011

Ajan, R. \& Hanafiah Juni, M. (2016). Socioeconomic Factors Associate with Smoking among Rural Adult Population in Negeri Sembilan, Malaysia. International Journal of Public Health and Clinical Sciences, 3(3), 2289-7577.

Balakrishnan, R., Allender, S., Scarborough, P., Webster, P. \& Rayner, M. (2009). The burden of alcohol-related ill health in the United Kingdom. Journal of Public Health, 31(3), 366-373. doi:10.1093/pubmed/fdp051

Beard, E., Brown, J., West, R., Angus, C., Brennan, A., Holmes, J., Kaner, E. et al. (2016). Deconstructing the Alcohol Harm Paradox: A population based survey of adults in England. PLoS ONE, 11(9), 1-17. doi:10.1371/journal.pone.0160666

Beard, E., Brown, J., West, R., Kaner, E., Meier, P. \& Michie, S. (2019). Associations between socioeconomic factors and alcohol consumption: A population survey of adults in England. PLoS ONE, 14(2), 1-15. doi:10.1371/journal.pone.0209442

Clay, J. M. \& Parker, M. O. (2018). The role of stress-reactivity, stress-recovery and risky decisionmaking in psychosocial stress-induced alcohol consumption in social drinkers. Psychopharmacology, 235(11), 3243-3257. doi:10.1007/s00213-018-5027-0

Collins, S. E. (2016). Associations between socioeconomic factors and alcohol outcomes. Alcohol Research: Current Reviews, 38(1), 83-94.

Dvorak, R. D., Pearson, M. R., Sargent, E. M., Stevenson, B. L. \& Mfon, A. M. (2016). Daily associations between emotional functioning and alcohol involvement: Moderating effects of response inhibition and gender. Drug and Alcohol Dependence, 163, S46-S53. doi:10.1016/j.drugalcdep.2015.09.034

Geusens, F., Vangeel, J., Vervoort, L., Loppevelde, W. Van \& Beullens, K. (2017). DispositionContent Congruency in Adolescents' Alcohol-Related Social Media (Self-) Effects: The Role of the Five Factor Model. BMC Public Health, 5(1), 1-8.

Goodman, F. R., Stiksma, M. C. \& Kashdan, T. B. (2017). Social Anxiety and the Quality of Everyday Social Interactions: The Moderating Influence of Alcohol Consumption. Behavior Therapy. doi:10.1016/j.beth.2017.10.002

Huckle, T., Romeo, J. S., Wall, M., Callinan, S., Holmes, J., Meier, P., Mackintosh, A. M. et al. (2018). Socio-economic disadvantage is associated with heavier drinking in high but not middle-income countries participating in the International Alcohol Control Study. Drug and Alcohol Review, 37(March), S63-S71. doi:10.1111/dar.12810

Juliana Gabrielle, M. O., Kelly Oliva, J., Raquel Conceição, F., Efigênia Ferreira, E. F., Míriam Pimenta, V. \& Patrícia Maria, Z. (2016). Risco de dependência do álcool: Prevalência, problemas relacionados e fatores socioeconômico. Ciencia e Saude Coletiva, 21(1), 17-26. doi:10.1590/1413-81232015211.00652015

McCartney, G., Bouttell, J., Craig, N., Craig, P., Graham, L., Lakha, F., Lewsey, J. et al. (2016). Explaining trends in alcohol-related harms in Scotland, 1991-2011 (I): The role of incomes, effects of socio-economic and political adversity and demographic change. Public Health, 132, 13-23. doi:10.1016/j.puhe.2015.12.013

Mehanović, E., Košir, M., Talić, S., Jeriček Klanšček, H. \& Vigna-Taglianti, F. (2020). Socioeconomic differences in factors associated with alcohol use among adolescents in Slovenia: a cross-sectional study. International Journal of Public Health, 65(8), 1345-1354. doi:10.1007/s00038-020-01460-w

Moan, I. S. \& Halkjelsvik, T. (2020). Socio-demographic differences in alcohol-related work impairment. Addiction. doi:10.1111/add.15202

Murphy, A., Roberts, B., Stickley, A. \& McKee, M. (2012). Social factors associated with alcohol consumption in the former soviet union: A systematic review. Alcohol and Alcoholism, 47(6), 711-718. doi:10.1093/alcalc/ags077

Quiroga, E., Pinto-Carral, A., García, I., Molina, A. J., Fernández-Villa, T. \& Martín, V. (2018). The influence of adolescents' social networks on alcohol consumption: A descriptive study of Spanish adolescents using social network analysis. International Journal of Environmental 
Research and Public Health, 15(9). doi:10.3390/ijerph15091795

Robinson, E., Oldham, M., Sharps, M., Cunliffe, A., Scott, J., Clark, E., Piercy, K. et al. (2016). Social Imitation of Alcohol Consumption and Ingratiation Motives in Young Adults. Psychology of Addictive Behaviors, 30(4), 442-449. doi:10.1037/adb0000150

Sadler, S., Angus, C., Gavens, L., Gillespie, D., Holmes, J., Hamilton, J., Brennan, A. et al. (2017). Understanding the alcohol harm paradox: an analysis of sex- and condition-specific hospital admissions by socio-economic group for alcohol-associated conditions in England. Addiction, 112(5), 808-817. doi:10.1111/add.13726

Shin, S. K., Sneed, S. E., Nennig, S. E., Cheek, S. R., Kinder, H. A., Solomon, M. G., Schank, J. R. et al. (2021). An Adolescent Porcine Model of Voluntary Alcohol Consumption Exhibits Binge Drinking and Motor Deficits in a Two Bottle Choice Test. Alcohol and Alcoholism, 56(3), 266274. doi:10.1093/alcalc/agaa105

Stafström, M. \& Agardh, A. (2013). Socio-economic determinants for alcohol consumption and heavy episodic drinking in a Ugandan student population. The International Journal of Alcohol and Drug Research, 1(1). doi:10.7895/ijadr.v1i1.40

Stapinski, L. A., Edwards, A. C., Hickman, M., Araya, R., Teesson, M., Newton, N. C., Kendler, K. S. et al. (2016). Drinking to Cope: a Latent Class Analysis of Coping Motives for Alcohol Use in a Large Cohort of Adolescents. Prevention Science, 17(5), 584-594. doi:10.1007/s11121-016$0652-5$

Thern, E. \& Landberg, J. (2020). Understanding the differential effect of alcohol consumption on the relation between socio-economic position and alcohol-related health problems: results from the Stockholm Public Health Cohort. Addiction. doi:10.1111/add.15213

Tran, T. D., Hammarberg, K., Kirkman, M., Thi, H., Nguyen, M. \& Fisher, J. (2020). Alcohol use and mental health status during the first months of COVID-19 pandemic in Australia. Journal of Affective Disorders, 277(July), 810-813. doi:10.1016/j.jad.2020.09.012

Vargas-Martínez, A. M., Trapero-Bertran, M., Mora, T. \& Lima-Serrano, M. (2020). Social, economic and family factors associated with binge drinking in Spanish adolescents. BMC Public Health, 20(1), 1-11. doi:10.1186/s12889-020-08605-9

World Health Organization. (2018). Global status report on alcohol and health 2018. Global status report on alcohol. doi:/entity/substance_abuse/publications/global_alcohol_report/en/index.html 